This chapter is forthcoming in Oreste Pollicino and Giovanni De Gregorio (eds), Blockchain and Public Law, Cheltenham: Edward Elgar, 2021. Please consult the volume for the final paginated version.

\title{
Blockchain and Citizenship: Uneasy Bedfellows
}

\author{
Oskar J. Gstrein, ${ }^{1}$ Dimitry Vladimirovich Kochenov² \\ ${ }^{1}$ Assistant Professor at the University of Groningen, Campus Fryslân, Data Research Centre, the \\ Netherlands. Research focuses on 'Human Dignity in the Digital Age', with particular emphasis on \\ Human Rights Law, Privacy, Surveillance, Digital Identity, and Governance of Emerging Technologies. \\ ${ }^{2}$ Professor of European Constitutional Law and Citizenship, University of Groningen, Faculty of Law, \\ The Netherlands. Research focuses on EU citizenship and European constitutionalism, with a \\ particular emphasis on the Rule of Law, EU federalism, EU external relations law, and EU Law of the \\ Overseas.
}

\begin{abstract}
Distributed Ledger Technology can be an effective tool for resource distribution. As individuals and organisations explore innovations which allow to redefine the rules of access, possession and sharing these developments also become important for the future of self-determination. Demonstrated through credit scoring and 'social credit systems', the identity of an individual is intertwined with resource access, possession and transferability. A key pre-requisite for participation is formal legal status, which translates to citizenship. However, many proponents of Distributed Ledger Technology focus predominantly on technological features and capabilities, which might enable the implementation of concepts such as decentralised governance, 'self-sovereign identity' management, and trust-less transactions based on 'zeroknowledge proof'. Nevertheless, such narrow consideration overlooks existing legal and political realities. Considering the lessons learned from citizenship, it becomes questionable whether Blockchain as player in the area of identity management will ultimately increase human dignity, or further manifest traditional patterns of discrimination and inequality.
\end{abstract}

\section{Keywords}

Blockchain, Citizenship, Privacy, Discrimination, Digital Identity, Self-Sovereign Identity. 


\section{Introduction}

In 2018 the multi-stakeholder initiative 'ID2020' was founded. With support of the United Nations High Commissioner for Refugees (UNHCR) this 'alliance' of technology start-ups, large corporations, civil society organisations and academic institutions produced a ten-point manifesto with the objective to 'get digital ID right'. The work of the alliance can be linked to similar initiatives, such as the 'Platform for Good Digital Identity' launched by the World Economic Forum in the same year, ${ }^{2}$ or the Identification for Development (ID4D) program that was already launched in 2014 by the World Bank. ${ }^{3}$ All of these initiatives are primarily addressing the concern that approximately 1 billion people globally face challenges in proving who they are because they lack formal documentation of their identity. ${ }^{4}$ Hence, it is impossible or cumbersome to access basic services such as healthcare, education, as well as financial or communication services. This has negative ramifications for individual development, and prosperity. ${ }^{5}$ Through establishment of coalitions, thought leadership and capacity building, as well as support for the creation of technical standards ID4D and the other alliances aim at contributing to achieving the United Nations Sustainable Development Goals (SDGs). ${ }^{6}$ Particularly SDG 16.9 is of importance, which sets the aim of providing legal identity for all, including birth registration by $2030 .^{7}$

Hence, much of the developments around Blockchain, identity and citizenship focus on geographical and issue areas where central or federated state administration has historically not worked well. ${ }^{8}$ However, also individuals residing in 'highly developed areas' of the world could experience a 'digital identity crisis'. While many of them possess potent passports and privileged citizenships, ${ }^{9}$ their individual and collective

\footnotetext{
1 'ID2020 | Manifesto' (ID2020) <http://id2020.org/manifesto> accessed 31 March 2020.

2 'Our Digital Future - Building an Inclusive, Trustworthy and Sustainable Digital Society. World Economic Forum Web Portal' $<$ http://www3.weforum.org/docs/WEF_Our_Shared_Digital_Future_Report_2018.pdf $>$ accessed 31 March 2020.

3 'Identification for Development 2018 Annual Report. World Bank ID4D Program' 1

<https://id4d.worldbank.org/sites/id4d.worldbank.org/files/2018_ID4D_Annual_Report.pdf> accessed 31 March 2020.

4 ibid 3.

5 ibid.

6 'Identification for Development 2019 Annual Report. World Bank ID4D Program' <http://documents.worldbank.org/curated/en/566431581578116247/pdf/Identification-for-Development-ID4D2019-Annual-Report.pdf> accessed 31 March 2020.

${ }^{7}$ Katina Michael and others, 'Privacy, Data Rights and Cybersecurity: Technology for Good in the Achievement of Sustainable Development Goals', 2019 IEEE International Symposium on Technology and Society (ISTAS) (2019).

${ }^{8}$ Andrej J Zwitter, Oskar Josef Gstrein and Evan Yap, 'Digital Identity and the Blockchain: Universal Identity Management and the Concept of the "Self-Sovereign" Individual' (2020) 3 Frontiers in Blockchain 7-10 <https://www.frontiersin.org/articles/10.3389/fbloc.2020.00026/abstract> accessed 11 May 2020.

${ }^{9}$ Kochenov, Dimitry and Lindeboom, Justin, Kälin and Kochenov's Quality of Nationality Index (1st edn, Hart Publishing) 9-36.
} 
autonomy is challenged by the omnipresence of 'surveillance capitalism' which has transformed personal data into a commodity. ${ }^{10}$ Additionally, the increasing risk of 'identity theft' is an expanding cybersecurity threat. ${ }^{11}$ Both of these developments spark critical evaluation of existing paradigms of identity management, especially as the digital layer of societal interaction evolves.

Sometimes hidden by the over-hyped debate around the market value of cryptocurrencies like Bitcoin, actors such as Kiva, ${ }^{12}$ Forus, ${ }^{13}$ Sovrin, ${ }^{14}$ uPort, ${ }^{15}$ or DanubeTech ${ }^{16}$ have developed platforms which explore the potential of Blockchain and related Distributed Ledger Technologies (DLT; e.g. Hyperledger Indy or Ethereum) for identity management. ${ }^{17}$ Furthermore, several players in the humanitarian sector are active in developing and deploying digital identity solutions. $^{18}$

At first sight the application of a technology like Blockchain for identity management might be surprising. The underpinning decentralised and distributed ledger for Bitcoin was initially designed to enable exchange of financial resources with independence from central institutions, rendering the necessity for stable legal and political frameworks meaningless as a consequence. ${ }^{19}$ Identity management is about exactly the opposite: legal statuses of citizenship and nationality being the products, precisely, of (state) institutions, Blockchain identity management is about reinforcing the understandings in politics and law, underpinning such status distributions: not your liberation project, given that the inequitably and neo-feudal nature of citizenship

\footnotetext{
${ }^{10}$ Shoshana Zuboff, 'Surveillance Capitalism and the Challenge of Collective Action' (2019) 28 New Labor Forum 10.

${ }^{11}$ Paul Simmonds, 'The Digital Identity Issue' (2015) 2015 Network Security 8 <http://www.sciencedirect.com/science/article/pii/S1353485815300696> accessed 31 March 2020.

12 'Kiva Protocol' (Kiva) <https://www.kiva.org/protocol> accessed 31 March 2020.

13 'Forus.Io' <https://forus.io/> accessed 31 March 2020.

14 'Home' (Sovrin) <https://sovrin.org/> accessed 31 March 2020.

15 'UPort - Tools for Decentralized Identity and Trusted Data' $<$ https://www.uport.me/> accessed 31 March 2020 .

16 'Danube Tech'<https://danubetech.com/> accessed 31 March 2020.

${ }^{17}$ Adam Piore On 02/22/19 at 11:07 AM EST, 'Can Blockchain Finally Give Us the Digital Privacy We Deserve?' (Newsweek, 22 February 2019) <https://www.newsweek.com/2019/03/08/can-blockchain-finallygive-us-digital-privacy-we-deserve-1340689.html> accessed 31 March 2020.

${ }^{18}$ Andrej Zwitter and Mathilde Boisse-Despiaux, 'Blockchain for Humanitarian Action and Development Aid' (2018) 3 Journal of International Humanitarian Action 16, 3-7 <https://doi.org/10.1186/s41018-018-0044-5> accessed 31 March 2020; Fennie Wang and Primavera De Filippi, 'Self-Sovereign Identity in a Globalized World: Credentials-Based Identity Systems as a Driver for Economic Inclusion' (2020) 2 Frontiers in Blockchain 14-17 <https://www.frontiersin.org/articles/10.3389/fbloc.2019.00028/full> accessed 31 March 2020 .

${ }^{19}$ Andrea Gaggioli and others, 'The Middleman Is Dead, Long Live the Middleman: The "Trust Factor" and the Psycho-Social Implications of Blockchain' (2019) 2 Frontiers in Blockchain 1-2 <https://www.frontiersin.org/articles/10.3389/fbloc.2019.00020/full> accessed 31 March 2020.
} 
is deeply contested and reducible to randomly-distributed economic rents. ${ }^{20}$ Moreover, lowering our level of abstraction, upon closer scrutiny it turns out that access, possession and the ability to redistribute resources is crucial for the constitution of individual identity in the eyes of society.

A useful analogy to illustrate this is credit scoring. In many countries opaque algorithms and procedures decide whether an individual is worthy of getting a loan. ${ }^{21}$ As a 2018 project by civil society organisation Algorithmwatch from Germany demonstrates, the inherent biases in these systems can negatively influence credit ratings for many years. Furthermore, they continue having negative consequences even if algorithms become available which produce more accurate and less discriminatory projections. ${ }^{22}$ In the People's Republic of China (PRC) such developments are taken further by exploring and implementing 'social credit scoring'. This rating system is also based on financial conduct at its core, yet adds further criteria of 'desirable' social behaviour to award individuals a score that can provide essential input for decisions. Depending on its concrete implementation, the social credit score determines whether one can take out a loan, start a(-nother) business, get promoted, book travel tickets on high speed trains and airplanes, or receive appropriate suggestions on dating platforms. ${ }^{23}$ While one might assume that particularly more educated and wealthy people rated through such a system label it as intrusive state surveillance, a 2019 study conducted by the Free University of Berlin finds broad support for this practice in large parts of the PRC's society. Potentially, the respondents of the survey value stability, reliability and security more than individual autonomy. ${ }^{24}$ The impact of COVID-19 and the emergence of digital contact tracing apps might further add to such scoring practices. ${ }^{25}$ At the bottom line social credit scoring performs the same function as the concept of 'good citizenship' in any society, be it democratic or totalitarian: it ensured a crucial share of complacency in the populations, reducing the autonomy of human action. ${ }^{26}$

\footnotetext{
${ }^{20}$ Dimitry Kochenov, Citizenship (MIT Press 2019); Joseph Carens, The Ethics of Immigration (Oxford University Press, Incorporated 2013) <http://ebookcentral.proquest.com/lib/rug/detail.action?docID=1336461> accessed 24 September 2020; Branko Milanovic, Capitalism, Alone (Harvard University Press 2019).

${ }^{21}$ Alicia Robb and David T Robinson, 'Testing for Racial Bias in Business Credit Scores' (2018) 50 Small Business Economics 429, 441-443 <https://doi.org/10.1007/s11187-017-9878-2> accessed 9 April 2020.

22 'SCHUFA, a Black Box: OpenSCHUFA Results Published' (AlgorithmWatch, 29 November 2018) $<$ https://algorithmwatch.org/en/schufa-a-black-box-openschufa-results-published/> accessed 31 March 2020.

23 'In China, a Three-Digit Score Could Dictate Your Place in Society' Wired <https://www.wired.com/story/age-of-social-credit/> accessed 31 March 2020.

${ }^{24}$ Genia Kostka, 'China's Social Credit Systems and Public Opinion: Explaining High Levels of Approval' (2019) 21 New Media \& Society 1565, 1588-1589<https://doi.org/10.1177/1461444819826402> accessed 31 March 2020.

${ }^{25}$ Qian Sun, 'Suzhou Introduced a New Social Scoring System, but It Was Too Orwellian, Even for China' (AlgorithmWatch, 14 September 2020) <https://algorithmwatch.org/en/story/suzhou-china-social-score/> accessed 25 September 2020.

${ }^{26}$ Kochenov (n 20).
} 
These short deliberations seem sufficient to emphasize that opportunities and limitations for the development of individual status and prosperity are directly tied to resource access and ownership. Hence, Blockchain-based applications deserve more attention as they become increasingly important for digital identity management. ${ }^{27}$ Proponents might see a golden opportunity for a new area of individual autonomy based on 'self-sovereignty' in 'cloud communities', ${ }^{28}$ as well as a bright future for privacy with the advent of 'zero-knowledge proof' which curtails the necessity to exchange personal data. ${ }^{29}$ We acknowledge such potential for meaningful progress. Cum grano salis though, we respectfully submit. Novel technological capabilities alone will not be enough to pave the way towards an increased level of human dignity and liberty in the digital age. Using Blockchain in citizenship and immigration-related identity management gives states a powerful tool to exacerbate the negative impact of the inequitable nature of the current citizenship world, as designed - particularly on the most needy and vulnerable populations, whose horizon of opportunities is already dramatically limited. In other words, we fear that rushed large-scale implementation is bound to better articulate and further expand existing inequalities. ${ }^{30}$ Once we consider these new developments through the lens of citizenship, discrimination, privacy, and governance the picture of the landscape becomes too complex to be addressed by approaches which solely focus on increased technical capabilities. More still: improving them is bound to result in a less equitable world, where the current nasty but sloppy injustices are polished to perfection.

\section{Methodology and central concepts}

The central question of this chapter is whether Blockchain-based identity management systems enable fairer access and distribution of resources. We understand the term fairer in relation to a reduction of structural bias, discrimination, as well as an increase of individual and collective self-determination. Such structural patterns become particularly visible when considering the history and reality of citizenship, which is currently the predominant formal mechanism to manage identity and resource access on a global scale. Citizenship works strongly at the expense of the former colonial populations, who in all cases get a much worse status less suited for global success as a result of the birth-time random distribution. 4/5ths of the

\footnotetext{
${ }^{27}$ Andreas Grüner, Alexander Mühle and Christoph Meinel, 'An Integration Architecture to Enable Service Providers for Self-Sovereign Identity', 2019 IEEE 18th International Symposium on Network Computing and Applications (NCA) (2019).

${ }^{28}$ Liav Orgad, 'Cloud Communities: The Dawn of Global Citizenship?' in Rainer Bauböck (ed), Debating Transformations of National Citizenship (Springer International Publishing 2018) 251-60 <https://doi.org/10.1007/978-3-319-92719-0_46> accessed 1 April 2020.

${ }^{29}$ Zwitter, Gstrein and Yap (n 8) 3.

${ }^{30}$ Branko Milanovic, Global Inequality : A New Approach for the Age of Globalization (Harvard University Press 2016) <http://search.ebscohost.com/login.aspx?direct=true \&db=nlebk\&AN=1213895\&site=ehostlive $\&$ scope $=$ site $>$ accessed 24 September 2020.
} 
world's population are thus the losers of what Shachar has powerfully described 'the birthright lottery'. ${ }^{31}$ Global citizenship and migration law is designed to keep it that way ${ }^{32}$ turning citizenship into one of the core tools of the promotion and preservation of inequality in the world today. ${ }^{33}$

Our task is thus, precisely, to ask the uncomfortable questions going beyond the debates surrounding the engineering and implementation of complex Blockchain systems. Indeed, describing, analysing and discussing this topic comes with the challenge that one aims at a constantly moving target. While the body of available academic literature is growing increasingly, ${ }^{34}$ much of it focuses on engineering aspects. Furthermore, there are currently no fully decentralised digital identity systems in use on large-scale which could inform this research. This also means that the implications of the emergence of DLT for traditional command and control structures, newer horizontal types of governance, or the concrete nature of decentralised network governance have not been mapped out as of yet. ${ }^{35}$

Nevertheless, new technical capabilities have opened up promising venues for digital identity management in the past several years. Potentially, Blockchain-based systems catalyse progress towards more human dignity in the digital age. For example, the concept of 'self-sovereign identity' is emerging. Although any universally and legally binding definition is missing, early pioneers such as Allen have described self-sovereign identity in 2016 as "[...] the next step beyond usercentric identity and that means it begins at the same place: the user must be central to the administration of identity." ${ }^{36}$ While Allen goes on to augment this definition in the form of ten principles, ${ }^{37}$ a potentially more useful general definition has been proposed by Wagner and colleagues who state that self-sovereign identity management is "[...] a model of digital identity where individuals and entities alike are in full control over central aspects of their digital identity, including their underlying encryption keys; creation, registration, and use of their decentralized identifiers [...] The architecture gives individuals and entities the power to directly

\footnotetext{
${ }^{31}$ Ayelet Shachar, The Birthright Lottery : Citizenship and Global Inequality (Harvard University Press 2009) $<$ http://search.ebscohost.com.proxy-ub.rug.nl/login.aspx?direct=true \&db=nlebk\&AN=328907\&site=ehostlive\&scope=site $>$ accessed 24 September 2020.

${ }^{32}$ Kochenov (n 20).

${ }^{33}$ Milanovic (n 30).

34 'Identity and Privacy Governance | Frontiers Research Topic'<https://www.frontiersin.org/researchtopics/9663/identity-and-privacy-governance> accessed 8 April 2020.

${ }^{35}$ Andrej Zwitter and Jilles Hazenberg, 'Decentralized Network Governance: Blockchain Technology and the Future of Regulation' (2020) 3 Frontiers in Blockchain <https://www.frontiersin.org/articles/10.3389/fbloc.2020.00012/full> accessed 31 March 2020.

${ }^{36}$ Christopher Allen, 'The Path to Self-Sovereign Identity'<https://www.lifewithalacrity.com/2016/04/the-pathto-self-soverereign-identity.html> accessed 8 April 2020.

${ }^{37}$ Wang and De Filippi (n 18) 9.
} 
control and manage their digital identity without the need to rely on external authorities." 38

This comes with implications for many different areas. Not only would it make the individual more independent from governmental authorities and powerful intermediaries which function as trust anchors (e.g. public administration, banks, insurance companies, notaries), also IT-juggernauts such as Facebook or Google would experience a considerable impact on their business models if self-sovereign identity management became a reality. The need to exchange 'raw personal data' reduces with self-sovereign identity management, especially if it is implemented in a way that includes 'zero-knowledge proof'.

To briefly elaborate on the latter, consider that an applicant needs to proof that he/she/it is of adult age to receive a benefit. Traditionally this means that the precise date of birth is shared by the applicant through a form, which is typically stored for data processing and analysis. This collection and sharing of personal data is usually based on explicit or implicit individual consent of the applicant, or on a legal obligation making it mandatory to disclose personal information. In such a situation, zero-knowledge proof would allow to only share a 'yes' or 'no' as an answer to the requirement ('being adult'). Hence, the 'raw' personal data (full date of birth) remains in the information sphere of the applicant and does not need to be stored elsewhere. We have outlined this in further detail in another publication, ${ }^{39}$ but for the purposes of this piece it suffices to briefly restate that zero-knowledge proof enables a user to construct a mathematical proof representing a correct mathematical output as 'reply' to a hidden input known only to that individual user.

Briefly switching from the technical to the legal domain, it needs be added that there is no overarching universal definition of identity in neither public nor private law. To the contrary, 'legal personhood' is addressed ad-hoc by legal regimes, typically relating to a specific context and moment of individual or social life. Legal personhood is important to be recognized as child or parent, being able to apply for citizenship, vote, etc. Furthermore, in the area of public international law and human rights law specifically, the concept of personality plays a role when it comes to rights such as privacy, freedom of thought, conscience and religion, or freedom of expression. On a universal level these are enshrined in Articles 17-19 of the 1966 International Covenant on Civil and Political Rights of the United Nations (ICCPR). Furthermore, one might also consider rights of a minority to adhere to a certain culture, language, or spiritual practice which is recognized in Article 27 ICCPR. $^{40}$ In the national legal order legal personhood plays an essential role for being able to have physical or intellectual property. In summary however, the legal system does

\footnotetext{
38 'Self-Sovereign Identity: A Position Paper on Blockchain Enabled Identity and the Road Ahead' 27 <https://www.bundesblock.de/wp-content/uploads/2019/01/ssi-paper.pdf> accessed 8 April 2020.

${ }^{39}$ Oskar J Gstrein and Dimitry Kochenov, 'Digital Identity and Distributed Ledger Technology: Paving the Way to a Neo-Feudal Brave New World?' (2020) 3 Frontiers in Blockchain 4 <https://www.frontiersin.org/articles/10.3389/fbloc.2020.00010/full> accessed 9 April 2020.

${ }^{40}$ Zwitter, Gstrein and Yap (n 8) 5-6.
} 
not have a consistent and holistic approach to what identity (or legal personhood) is or should be. ${ }^{41}$ This is also one of the main reasons why it is challenging to design technologies for universal identity infrastructures.

In this chapter we consider how current state-of-the-art Blockchain-based digital identity systems aim at implementing these concepts in real life. We evaluate these efforts highlighting aspects relating to governance, citizenship, bias and discrimination, as well as privacy and in particular the use of biometric data for identification. We present two state-of-the art projects which are based on DLT. One of them is being implemented in Sierra Leone, while the other one took place in the Netherlands. We enrich this set of data with observations of two non-Blockchain based identity systems from Estonia and India, which are particularly noteworthy because of their architectural features and their large user bases. While both of these are not decentralised DLT systems, they share several key characteristics. We use the insights from these observations as basis for speculation which challenges DLT faces if it becomes a standard tool for large-scale identity management. Subsequently to the presentation of the case-studies, we discuss opportunities and limitations by linking these developments to the world of citizenship. In conclusion, we reflect whether and how Blockchain-based identity management might become a building-block for a better future.

\section{Blockchain identity case studies}

\section{Kiva Protocol}

Kiva is a non-profit entity based in San Francisco. Established in 2005, it aims at increasing financial inclusion and access to financial services. ${ }^{42}$ Since September 2018 it has started to implement Kiva Protocol, a digital identity management system based on Hyperledger Indy as Blockchain layer. ${ }^{43}$ The protocol is among the first Blockchain-based identity systems to have received the ID2020 certification mark in March $2020 .{ }^{44}$ Particularly noteworthy is a project in the West-African country of Sierra Leone, where Kiva Protocol is implemented with the vision to establish selfsovereign identity management for its 7 million population. One of the main objectives is to provide a safe and reliable Know-Your-Customer (KYC-)mechanism. Most individuals in Sierra Leone lack formal proof of their identity or credit history, which makes it almost impossible to apply for a loan. This deprives individuals of financial opportunity and the society of economic development. ${ }^{45}$ Hence, the new system has the objective of building the bridges between the public institution issuing

\footnotetext{
41 ibid 6.

42 'About' (Kiva) <https://www.kiva.org/about> accessed 13 April 2020.

43 'Kiva Protocol' (n 12).

${ }^{44}$ Adam Cooper, 'ID2020 Certification Report' 10.

${ }^{45}$ Wang and De Filippi (n 18) 11-14.
} 
civil identification, the central bank of Sierra Leone (in particular the Credit Reference Bureau), financial institutions and the individual applicant. ${ }^{46}$ All of the mentioned institutions become trust anchors verifying credentials of individuals, which also means that their reputation is at stake beyond this project.

Kiva provides all citizens of Sierra Leone with a digital identity verified by the government which comes with a private/public key pair to cryptographically sign identity claims. While biometrics are being used to identify individuals and connect them to their digital identities, other 'objective' attributes such as date/place of birth are used as well. Hence, the 'authority' of biometrics as most accurate - or 'authoritative' - means of identification is relativized through the design of the system. This is a deliberate choice that deserves attention. Another interesting feature of this system is that it allows individuals to have not only one root-identity. The protocol also allows the creation of several persona by creating sub-identities, typically tied to one lending process. Any request for interaction with these identities, such as permission to read records, as well as revocation of access are stored on the Blockchain layer with timestamps. ${ }^{47}$

While this system is designed to preserve individual autonomy and privacy by requiring the consent of the individual at the start of each interaction, the daily reality of Sierra Leone inhabitants makes it impossible to store all sensitive information (private keys, files that link root-identifiers with sub-identifiers, identity claims, etc.) locally on devices controlled by only one individual. ${ }^{48}$ While digital devices capable of storing digital identities such as smartphones are increasingly common, this is a serious limitation in the short- to medium-term. Many individuals will have to share devices (e.g. in a family), or rely on institutions and proxies. In turn, this might make them vulnerable or exploitable.

Another challenge is the back-up mechanism for digital identities. If a device breaks or gets inaccessible, there needs to be a way of restoring an identity to make sure the identity claims can be restored. In this project, ultimately the government of Sierra Leone serves as 'guardian' for the Kiva backup servers which have to be located on the territory of the country. The backup keys are encrypted and can only be accessed through a multi-stage process involving identification using biometrics or a PIN code. ${ }^{49}$ However, it seems obvious that the reliability and legitimacy of such a process depends ultimately on sound institutional checks and balances within the Sierra Leone government and its authorities.

\section{Forus}

\footnotetext{
${ }^{46}$ Cooper (n 44) 1.

${ }^{47}$ Wang and De Filippi (n 18) 11.

48 ibid 12.

${ }^{49}$ ibid.
} 
Forus is a non-profit foundation (stichting) based in the city of Groningen in the north of the Netherlands..$^{50}$ It is building an open-source platform for digital-identity which adds features and use cases incrementally. ${ }^{51}$ The platform is centred around four roles: The applicant who wishes to gain a particular benefit, the provider of a service/good, the sponsor, and validating parties. The general vision of Forus is to develop applications for the public domain, which enable individuals or users to interact in a networked environment through a platform with decentralised governance. Ultimately, it should be possible to enable individuals to interact with governments/benefactors in a trusted manner respecting private data, while at the same time reducing dependency on intermediaries and increasing efficiency. Hence, by striving to build a framework based on decentralization there is no central party on which the users of the platform solely depend.

From 1 September 2017 to 31 March 2018 the first application of Forus was implemented in the small community of Zuidhorn/Westerkwartier. ${ }^{52}$ The main objective was to digitize social service provision relating to the area of child-welfare (Kindpakket).$^{53}$ Such community-based approaches seem particularly promising for the development of digital identity management platforms. ${ }^{54}$ Projects like this enable tailored solutions for the incremental adoption of DLT. In the Netherlands most individuals own a smartphone and have reliable Internet connectivity. This means it is relatively easy to build on pre-existing systems and infrastructure when attempting to establish self-sovereign identity management. ${ }^{55}$

The implementation of the platform circles around a smartphone application called 'Me'. It contains and manages all claims building the individual digital identity and functions as wallet for vouchers which can be scanned through QR-codes. Some fundamental claims (e.g. citizenship, date of birth) have to be verified by validating parties such as public institutions or notaries. Once the application is installed and essential claims have been verified, the applicant gains access to a portal where benefits such as the child-welfare package are available. Funding schemes can be initiated by municipalities as in this case. However, in principle also nongovernmental organisations or other benevolent actors could setup funds. These sponsors also determine the criteria for individuals to become eligible (e.g. having a home address with a certain postal code, a certain annual income, number of children). Once the criteria for the fund are decided and the service providers/merchants have been identified, the fund becomes available on the portal.

\footnotetext{
50 'Forus.Io'<https://forus.io/geschiedenis> accessed 14 April 2020.

51 'Forus' (GitHub) <https://github.com/teamforus> accessed 14 April 2020.

${ }^{52}$ Martin Velthuijs, 'Forus, Gemeente Zuidhorn, Berenschot, Platform Forus garandeert de betrouwbaarheid, veiligheid en toegankelijkheid'.

${ }^{53}$ Information in this section was collected throughout several longer conversations with the developers.

${ }^{54}$ Gstrein and Kochenov (n 39) 5.

${ }^{55}$ Zwitter, Gstrein and Yap (n 8) 2.
} 
If an individual applies, the eligibility criteria are checked without the exchange of raw personal data, only based on zero-knowledge proof.

Once application was successful, the applicant receives certain tokens (e.g. vouchers to enter the local swimming pool, to send children to music lessons, dance lessons, language courses, etc.) or actual currency wired through bank transfer. It is important to mention that a bank is necessary to build the bridge between the digital identity management system and the monetary system. Initially this proved to be a challenge, but ultimately a Dutch online bank provided the technical and service capabilities to facilitate the cashflow between the municipality, the applicant, and the service providers. Based on this experience Forus has increasingly worked on the capabilities to take a more central role in the processing of payments. This needs to be done in compliance with Anti-Money Laundering (AML-)regulation, which remains particularly challenging when using cryptocurrency. ${ }^{56}$

Besides choosing either for currency or tokens, this system can also be used in a hybrid mode. This means that applicants receive partly tokens and partly currency. The use of tokens allows the sponsor to determine more granularly which goods or services applicants can acquire. On the one hand, this might be useful to prevent abuse of the funds (e.g. spending resources on goods or services which are not targeted by the program). On the other hand, this aspect can also be viewed as problematic feature since it restricts the freedom of individuals and households. Therefore, a case by case assessment should be made as to whether such a limitation is necessary and proportionate.

\section{Relevant aspects of Non-Blockchain based identity systems}

\section{Referential value}

DLT-based systems enabling decentralised identity management are still in their infancy. Hence, there is little experience in how society interacts with them. However, the field of digital identity management is not restricted to Blockchain. For example, technologies to identify people based on biometric data have become standard in passports since 9/11 attacks. ${ }^{57}$ Additionally, biometric sensors are used increasingly across all branches of the public sector, ${ }^{58}$ and have been integrated in very large numbers of mobile devices over the last years. ${ }^{59}$ Technologies like this

\footnotetext{
${ }^{56}$ Malcolm Campbell-Verduyn, 'Bitcoin, Crypto-Coins, and Global Anti-Money Laundering Governance' (2018) 69 Crime, Law and Social Change 283 <http://link.springer.com/10.1007/s10611-017-9756-5> accessed 16 April 2020.

${ }^{57}$ Ben Schouten and Bart Jacobs, 'Biometrics and Their Use in E-Passports' (2009) 27 Image and Vision Computing 305 <http://www.sciencedirect.com/science/article/pii/S0262885608001200> accessed 17 April 2020 .

58 ‘Biometrics Revolutionise Public Sector Data Security’ (2017) 2017 Biometric Technology Today 2 <http://www.sciencedirect.com/science/article/pii/S0969476517301741> accessed 17 April 2020.

59 'Mobile Biometrics Revenues Predicted to Boom' (2017) 2017 Biometric Technology Today 3 <http://www.sciencedirect.com/science/article/pii/S0969476517301613> accessed 17 April 2020.
} 
are reused in one way or another for decentralised DLT-based identity management systems. Hence, it makes sense to consider the challenges more conventional digital identity systems faced in the past, as well as to explore the problematic aspects that continue to exist in the present. For the purposes of this chapter we have decided to focus on two digital identity case-studies from Estonia and India.

With its focus on cross-border activities and some centrally managed Blockchain components, the Estonian e-residency program is relevant due to its objectives and architectural features. ${ }^{60}$ Acknowledging its centralised management, it shares a large number of design features with the digital identity management systems we presented in the previous section. The Indian Aadhaar program is the largest digital identity program in the world in terms of registered users. Worries exist about severe negative consequences for individual and collective autonomy. ${ }^{61}$ Furthermore, Aadhaar's heavy dependency on biometrics for identification catalysed a national discussion on the status of the right to privacy. ${ }^{62}$

\section{E-Residency Estonia}

Estonia is generally considered as one of the front-runners in digital administration and e-governance. ${ }^{63}$ Since the Baltic country re-gained independence with the fall of the Soviet Empire in 1991, technology has been used as a means to rebuild national identity and develop the countries 'brand'. ${ }^{4}$ If one considers that Estonia has fewer inhabitants than the city of Vienna on a territory with a complex geopolitical position, it becomes understandable why growth in the digital domain is appealing. Hence, once the digital transformation for its citizens was almost completed, Estonia developed an individual incentive based scheme for e-residency starting in 2014 . $^{65}$ At its $5^{\text {th }}$ anniversary on December 12019 the program had attracted 62,707 new 'eresidents' from $160+$ countries, who had established more than 10,000 companies. ${ }^{66}$

\footnotetext{
${ }^{60}$ Clare Sullivan and Eric Burger, 'E-Residency and Blockchain' (2017) 33 Computer Law \& Security Review 470, 472-479 <http://www.sciencedirect.com/science/article/pii/S0267364917300845> accessed 17 April 2020.

${ }^{61}$ Pawan Singh, 'Aadhaar and Data Privacy: Biometric Identification and Anxieties of Recognition in India' (2019) 0 Information, Communication \& Society 1 <https://doi.org/10.1080/1369118X.2019.1668459> accessed 17 April 2020.

62 Tathagata Satpathy, 'The Aadhaar: "Evil” Embodied as Law' (2017) 7 Health and Technology 469 <http://link.springer.com/10.1007/s12553-017-0203-5> accessed 17 April 2020.

63 'Estonia Optimistic about Digital Future after E-Government Drive' (4 December 2019) <https://www.ft.com/content/e207b2a6-f973-11e9-a354-36acbbb0d9b6> accessed 17 April 2020.

${ }^{64}$ Piia Tammpuu and Anu Masso, "Welcome to the Virtual State": Estonian e-Residency and the Digitalised State as a Commodity' (2018) 21 European Journal of Cultural Studies 543, 544 <https://doi.org/10.1177/1367549417751148> accessed 17 April 2020.

${ }^{65}$ Gstrein and Kochenov (n 39) 3-4; Piia Tammpuu and Anu Masso, 'Transnational Digital Identity as an Instrument for Global Digital Citizenship: The Case of Estonia's E-Residency’ (2019) 21 Information Systems Frontiers 621, 623-624 <https://doi.org/10.1007/s10796-019-09908-y> accessed 17 April 2020.

${ }^{66}$ Ott Vatter, 'Five Years of E-Residency: Past, Present and Future' (Medium, 16 December 2019) <https://medium.com/e-residency-blog/five-years-of-e-residency-past-present-and-future-3df1786aa5ca> accessed 18 April 2020.
} 
Estonia's e-residency program is the first of its kind. The program has the primary objectives of supporting the country's economy by transforming Estonia into an attractive business hub, and to establish it as an important player in Europe and the world. ${ }^{67}$ It is particularly striking how little is required to gain the right to 'virtual residency', which comes with the privilege of using Estonia as a base for business. The application can be done online. It requires to present a valid national ID, a photo of the applicant, as well as and the payment of an administrative fee. Once a background check has been carried out by the Estonian Police and Border Guard, the applicant has to go to a designated collection site within or outside Estonia (e.g. an embassy) to provide fingerprints and to collect the e-Resident ID card and a card reader which are both secured. ${ }^{68}$

According to a 2019 study the motives for e-residency are: to run a location independent international business (45 percent), interests in business activity or Estonia ( 25 percent), to be a 'fan of e-residency' (14 percent), as well as others (16 percent) including professional interests, living in or visiting Estonia, promoting the development of science, education or culture in Estonia, and the use of e-services or secure technology for authentication. ${ }^{69}$ The same study finds that applicants are predominantly male and initially came from countries with close historical or territorial ties to Estonia (e.g. Finland, Russia, Ukraine). The relative proportion of applicants from EU and non-EU countries matches almost exactly, with a stronger trend towards applications from non-EU countries in recent years. It is still unclear how Brexit will influence these numbers. Probably most interestingly, the study finds that most applicants come from countries which already have a high degree of egovernance services available. In other words, it seems that Estonian e-residency is mostly appealing to individuals who already have plenty of opportunities in this area. However, the authors caution that more data on this aspect would be helpful to understand this issue in better detail. ${ }^{70}$

Despite the respectable number of e-residents the program has experienced several challenges. While it is relatively easy to have an Estonian digital identity, that does not mean that Estonian banks and other service providers are free from abiding by European and international regulation, making it virtually impossible for the holders of e-Residences to benefit from their fancy IDs without actually moving to Estonia, which cannot be done on the basis of the e-Residence document, the latter expressly disconnected from such options. The Estonian government tries to address the problems with the development of 'e-Residency 2.0'. The objectives and strategy for this upgrade are presented in a 'White Paper', ${ }^{71}$ which has been

\footnotetext{
${ }^{67}$ Tammpuu and Masso (n 65) 623-625.

${ }^{68}$ Sullivan and Burger (n 60) 471-473.

69 Tammpuu and Masso (n 65) 627.

70 ibid 629-632.

71 'E-Residency+2.0+white+paper+English.Pdf' <https://s3.eu-central-1.amazonaws.com/ereswhitepaper/eResidency+2.0+white+paper+English.pdf $>$ accessed 17 April 2020.
} 
published in the context of the fifth anniversary. It remains to be seen how these changes will be implemented in the coming years. In the meanwhile, Dubai and Lithuania have also announced their desire to create similar e-residence schemes. ${ }^{72}$ All in all, the conflict between the 'digital' and the 'real' is clear in the case of Estonian e-Residence: while the status is attractive because it potentially empowers someone residing far away from Estonia to improve the efficiency of public service provision in relation to running a business without a need to emigrate, it is precisely the fact that the beneficiaries stay at home and thus cannot be checked the usual way by the Estonian banks in accordance with all the regulations in force, which presumes that holding a residency of a place where you have never been is somewhat abnormal, make the practical advantages of this forward-looking programme negligible.

\section{Aadhaar}

'Modern governance rests on the assumption that the government must know its population and, in order to improve life, be able to productively influence the behaviour of individuals. ${ }^{73}$ This also seems to be true for India, which has historically struggled to register its population comprehensively. In 2008 the four most frequently used identity management systems (40 million passports, 70 million Permanent Account Numbers for use by the Indian Income Tax Department, 220 million 'Ration Cards' issued by state governments to allow for the purchase of essential commodities, 500 million voter IDs) covered only a fraction of the world's second largest population. ${ }^{74}$ Having an ID does not mean full security either: citizenship deprivations with backfiring force are a norm, as is proven by the example of Assam giving the whole system a haphazard tint: the Indian State itself presumes that its own registry of citizens is not to be trusted. ${ }^{75}$

In an attempt to establish a comprehensive identification mechanism, the Indian government established the Unique Identification Authority (UIDAI) in $2006 .{ }^{76}$ From 2010 a Unique Identity (UID) was rolled out which consists of twelve numbers. The Aadhaar system ('foundation' or 'support' in English) links this identifier to an individual. ${ }^{77}$ From the beginning, Aadhaar was designed to be a game changer and

\footnotetext{
${ }^{72}$ Vatter (n 66).

${ }^{73}$ Ursula Rao and Vijayanka Nair, 'Aadhaar: Governing with Biometrics' (2019) 42 South Asia: Journal of South Asian Studies 469, 471 <https://www.tandfonline.com/doi/full/10.1080/00856401.2019.1595343> accessed 17 April 2020.

${ }^{74}$ Frances Zelazny, 'The Evolution of India's UID Program Lessons Learned and Implications for Other Developing Countries' [2012] CGD Policy Paper <http://www.cgdev.org/content/publications/detail/1426371>.

75 'Assam NRC: What next for 1.9 Million “stateless” Indians?' BBC News (31 August 2019) <https://www.bbc.com/news/world-asia-india-49520593> accessed 24 September 2020.

76 'Home' (Unique Identification Authority of India | Government of India) <https://uidai.gov.in/> accessed 18 April 2020.

${ }^{77}$ Rao and Nair (n 73) 469.
} 
seems to have delivered. According to the dashboard of the Unique Identification Authority of India (UIDAI) 1,257,491,398 digital identities had been generated by April $182020 .{ }^{78}$ Almost all regions of India are comprehensively covered. This translates to a relative penetration of the population that is far beyond 90 percent. By number of enrolled persons, it is the largest digital identity system in the world. ${ }^{79}$

Accordingly, large amounts of personal data have been collected (e.g. date of birth, parent's names), including biometric measurements of the iris and fingerprints in particular. ${ }^{80}$ While this information is being held in a central database, the use of biometrics is also considered as a possible means to link digital wallets to their owners, ${ }^{81}$ which makes this aspect also relevant for decentralised DLT-based identity management systems.

The structured and automated use of that much personal information comes with several challenging aspects. Standardisation might bring benefits for efficiency and productivity of a large-scale system, but it also has a tendency of failing to recognise the needs of the poor and less privileged. Being identifiable is not necessarily positive for everyone, and the improved management capabilities of public administration can result in the loss of individual and group autonomy. Furthermore, Aadhaar struggled for a long time with the reliability of identification based on biometric information. ${ }^{82}$

Beyond these concerns, one of the biggest problems with the adoption of Aadhaar was the lack of a sound governance framework at its inception. Such a framework should have specified legitimate purposes for the use of the system before implementation, including individual safeguards and remedies, oversight mechanisms, as well as mechanisms to guarantee transparency and accountability. The main purpose of Aadhaar is to help the government in providing social welfare (e.g. food subsidies). However, the more granular understanding of the population comes with worries about mass-surveillance and unwarranted state intervention. ${ }^{83}$ Privacy concerns relate particularly to identification without consent, correlation of identities across multiple domains, illegal tracking of individuals, as well as identity theft. ${ }^{84}$ Most importantly, the system does not protect anyone from arbitrary deprivation of citizenship, which is not unheard of in the country where millions of

\footnotetext{
78 'Aadhaar Dashboard' < https://uidai.gov.in/aadhaar_dashboard/india.php> accessed 18 April 2020.

${ }^{79}$ Rao and Nair (n 73) 469.

${ }^{80}$ Silvia Masiero, 'Explaining Trust in Large Biometric Infrastructures: A Critical Realist Case Study of India's Aadhaar Project' (2018) 84 The Electronic Journal of Information Systems in Developing Countries e12053, 4 <http://onlinelibrary.wiley.com/doi/abs/10.1002/isd2.12053> accessed 18 April 2020.

${ }^{81}$ Primavera De Filippi and Aaron Wright, 'Blockchains, Bitcoin, and Decentralized Computing Platforms', Blockchain and the Law (Harvard University Press 2018) 14-16 <https://www.jstor.org/stable/j.ctv2867sp.4> accessed 18 April 2020.

${ }^{82}$ Singh (n 61) 11-13.

${ }^{83}$ Usha Ramanathan, 'A Unique Identity Bill' (2010) 45 Economic and Political Weekly 10 <https://www.jstor.org/stable/20764328> accessed 18 April 2020; Rao and Nair (n 73) 481.

${ }^{84}$ Subhashis Banerjee and Subodh Sharma, 'Privacy Concerns with Aadhaar' < http://doi.org/10.1145/3353770> accessed 18 April 2020.
} 
stateless people have been produced over the recent years with no relation to their ability to identify themselves and even attest their identity with valid Indian passports. ${ }^{85}$ As evidence underlining such assessment mounts, Aadhaar has recently been described as 'tech-weapon of mass exclusion'. ${ }^{86}$ Following widespread public and international discussion, the Indian Supreme Court delivered a landmark judgment on August $242017 .{ }^{87}$ While the system was not declared unconstitutional, the focus on the individual and human dignity were restored to some degree. Furthermore, it was clarified that the use of the system needs be more tightly focused on the initially proclaimed purposes. The judges also made clear that Aadhaar must not be abused to interfere in sensitive areas of the private lives of individuals, such as sexual conduct or preferences.$^{88}$ Most crucially, however, as is clear from the context of citizenship deprivation in Assam, any identity system, however perfect, is most of all a matter of politics, not engineering.

\section{Discussion}

The case-studies above clearly hint at the problems that necessarily arise at the interface of technology and the real world of identity management. Just as the great ideas harboured by the designers of Estonian e-citizenship or those willing to document the inhabitants of India, got severely corrected by the real world practices, any technological approach to identity management is bound to start with questioning the good that the purported technological solution is about to generate. While the level of scrutiny would necessarily vary, at least four basic questions to investigate the usefulness of DLT based applications proposed by Zwitter and Boisse-Despiaux are of relevance: ${ }^{89}$

1. Do the benefits of DLT justify the costs of development and scaling?

2. Is the application (e.g. digital identity management) demanding decentralization and built-in trust through transparency?

3. Does the ledger need to be immutable?

\footnotetext{
${ }^{85}$ Regina Menachery Paulose and Regina Menachery Paulose, 'A New Dawn? Statelessness and Assam' [2019] Groningen Journal of International Law; Vol 7 No 1 (2019): International Law: Open Issue; 99-111 <https://ugp.rug.nl/GROJIL/article/view/35703> accessed 24 September 2020.

${ }^{86}$ Subhashish Panigrahi, 'Is India's Digital ID System, Aadhaar, a Tech Solution for a Socio-Economic Problem? · Global Voices' (Global Voices, 16 August 2020) <https://globalvoices.org/2020/08/16/is-indiasdigital-id-system-aadhaar-a-tech-solution-for-a-socio-economic-problem/> accessed 24 September 2020.

${ }^{87}$ Menaka Guruswamy, 'Justice K.S. Puttaswamy (Ret'd) and Anr v. Union of India and Ors' (2017) 111 American Journal of International Law 994 <http://www.cambridge.org/core/journals/american-journal-ofinternational-law/article/justice-ks-puttaswamy-retd-and-anr-v-union-of-india-andors/ED631B8F922039BEC5400086C8E34338> accessed 18 April 2020.

${ }^{88}$ ibid 996-1000.

${ }^{89}$ Zwitter and Boisse-Despiaux (n 18) 6.
} 
4. Does the final application comply with applicable legal and moral frameworks, ethical principles and human rights?

When implemented without much critical thinking about existing identity structures, DLT-based identity systems precisely harm individual independence, instead of enhancing it. This is because in a physical world where states reign supreme taking hold of the lives of those they irreversibly and unilaterally claim as citizens, DLT operation will be at the service of the states, rather than the individual. DLT might perfect the suffocating bonds, rather than freeing from them. It seems not unlikely that DLT-based identities would simply clone conventional identities, especially given the predominance of states and territoriality as the main idea behind the core aspect of citizenship.

Concrete examples are easy to come by. Should someone be assigned a humiliating set of liabilities in real life - e.g. a Central African Republic citizenship - instead of a noble and democratic status - e.g. citizenship of France - virtual nations and whatever technology in the world will not change anything from the perspective of individual rights, and human dignity. The lack of any rights worldwide coming with some citizenships as opposed to a bundle of rights coming with others can be measured. By comparing the Gross domestic product (GDP), Human Development Index (HDI), travel freedom, settlement and work rights abroad it is easy to see why being French - a status welcoming you to the job market of 41 countries - is infinitely better than being a citizen of the Central African Republic. ${ }^{90}$ Hence, the actual problem derives from already existing real-world inequalities between identities and citizenships. It is not only that citizenships by definition exclude, the difference between citizenships matters. ${ }^{91}$

Branko Milanovic has outlined that inequalities now rest between states, rather than within national borders: the harshest inequalities are now spacialised, not classbased, which only boosts the importance of citizenship as a status of tying owners to space, as a global guarantor and reinforcer of inequalities. ${ }^{92}$ Hannah Arendt's concept of a 'right to have rights' citizenship for individuals who would otherwise be stateless, is a status associated with rights in a handful of countries only. ${ }^{93}$ In many others, it is a severe and undeserved liability with sometimes fatal consequences. If cloud communities, digital identity projects, and virtual nations are not addressing this issue in their design, these fundamental realities will remain the same.

\footnotetext{
${ }^{90}$ Kochenov, Dimitry and Lindeboom, Justin, Kälin and Kochenov's Quality of Nationality Index (1st edn, Hart Publishing 2020).

${ }^{91}$ Dimitry Kochenov, 'Escapist Technology in the Service of Neo-Feudalism' in Rainer Bauböck (ed), Debating Transformations of National Citizenship (Springer International Publishing 2018) 321-324 <https://doi.org/10.1007/978-3-319-92719-0_57> accessed 24 September 2020.

${ }^{92}$ Milanovic (n 30).

93 Natalie Oman, 'Hannah Arendt's "Right to Have Rights": A Philosophical Context for Human Security' (2010) 9 Journal of Human Rights 279, 280-289 <https://www-tandfonline-com.proxyub.rug.nl/doi/full/10.1080/14754835.2010.501262> accessed 24 September 2020.
} 
Both of the DLT-based identity systems in this chapter have in common that they focus on solving one concrete problem, using a process of incremental implementation. Such approaches seem more promising than purely technology focused projects that fail to create impact in the non-digital domain (e.g. conventional cryptocurrencies), or very centralised and top-down digital identity programs that demand individuals to 'normalise' themselves in order to fit pre-defined categories. ${ }^{94}$ However, it is also obvious that such systems require basic technical infrastructure to be in place, which needs to work reliably, and reach all parts of the population. Furthermore, existing approaches to governance and institutional competencies might have to be reconsidered or shifted. Finally, the technology can only work if a process of education takes place, which informs officials how to properly run the system, and which explains to users which kind of benefits they might be able to reap.

While the implementation of Kiva potentially results in simpler and more secure (micro-)lending from a business perspective, it remains to be seen how much it will also result in increased individual autonomy. Despite its vision of self-sovereignty and decentralisation, the current implementation of this system still heavily relies on non-digital elements, such as physically tangible money bills once a loan is granted. Arguably, much of the success of Kiva Protocol hinges on the technical and organisational capabilities of individuals who increasingly gain ownership of smartphones and might be interested to learn how the system works. If the technical implementation of Kiva Protocol is not paralleled by such a process of societal innovation and development, the more granular, formally recognised digital identities remain on Kiva backup-servers in guardianship, managed on behalf of the citizens of Sierra Leone on the basis of formal consent. ${ }^{95}$

Furthermore, also in the Netherlands societal realities limit the implementation of the vision behind Forus in its pure form. As long as it is not possible to use cryptocurrencies like Ether for common every-day transactions, DLT is primarily restrained to keeping records of transactions that reference to the digital IDs stored in applications like 'Me'. Furthermore, in this case it was not pragmatic to run the entire project using only DLT, since the larger architecture (e.g. creating an entire ecosystem for the management of a self-sovereign identity with all of the attributes of a person, transferring all of the existing administrative information from traditional databases on distributed-ledger based systems, etc.) would have made it impossible to prove the concept. Such pragmatic design choices raise questions on the added value of Blockchain and DLT in the first place. ${ }^{96}$ Nevertheless, the outcomes and findings of the pilot suggested that it seems possible to continue along the path towards self-sovereign identity management. As the Forus platform continues to

\footnotetext{
${ }^{94}$ Zwitter, Gstrein and Yap (n 8) 10-12.

${ }^{95}$ Wang and De Filippi (n 18) 13.

96 Jesse Frederik, 'Blockchain, the Amazing Solution for Almost Nothing' (The Correspondent, 21 August 2020) <https://thecorrespondent.com/655/blockchain-the-amazing-solution-for-almost-nothing/86649455475f933fe63> accessed 26 September 2020.
} 
grow and evolve, applications for bigger municipalities have and continue to be rolled out in the Netherlands. ${ }^{97}$

\section{Conclusion: The future of Citizenship?}

In summary, the answer to a question 'what would happen if DLT based digital identity was applied globally and became the standard tool of choice, eventually digitizing citizenship?' - is thus quite clear, and it is not a positive one. If digital identity management driven predominantly by concerns relating to technological feasibility was to replace traditional identity management and citizenship, this would reinforce the random segregation of the global population into relatively closed groups enjoying legal statuses. ${ }^{98}$ Some of these DLT-based digital identities will come with far-reaching rights, whereas others will predominantly represent solely bitter liabilities. Hence, digitized identity management will first and foremost make this segregation process at the heart of the modern operation of citizenship more granular, and effective.

Citizenship's core function throughout history has been to establish and police global race- and wealth-based hierarchies, as well as normalize and reinforce sexism. It took US women almost a hundred years to get the right to vote, ${ }^{99}$ and women in the Swiss canton of Appenzell-Innerrhoden had to wait until a 1991 decision of the Federal Supreme Court. ${ }^{100}$ Compared with women in 'developed countries', individuals living in colonial territories fared even worse: to say that women (and men) have a right to vote in the Central African Republic - to pick the previous example - is to utter a nonsense statement. The same applies to the majority of states in the world, should we believe The Economist Democracy Index. ${ }^{101}$ If not an autocracy, the majority of citizens of our planet inhabit a hybrid regime. While African Americans have not been enjoying the same rights as 'Caucasian' US citizens historically, the same is true for those with different ethnic backgrounds living in European and Asian empires. The point is fundamental: the status of citizenship has traditionally been racist, excluding millions from the recognition of full dignity and rights based - most frequently - on the pigmentation of the skin. Identity management systems which made a consistent application of the global segregation based on an arbitrarily assigned claim of authority over individuals - e.g. citizenship - are the same that ensured the sexist and racist components of the status.

\footnotetext{
97 'Nijmegen Webshop' <https://inkomensondersteuning.nijmegen.nl/> accessed 16 April 2020.

${ }^{98}$ Kochenov (n 20); Shachar (n 31).

${ }^{99}$ Susan Goodier and Karen Pastorello, 'Conclusion:: Winning the Nation', Women Will Vote (Cornell University Press 2017) <http://www.jstor.org/stable/10.7591/j.ctt1w0d9sr.14> accessed 24 September 2020.

${ }^{100}$ Bundesgericht Schweiz, ‘116 IA 359’ (27 November 1990) $<$ http://relevancy.bger.ch/php/clir/http/index.php?highlight_docid=atf\%3A\%2F\%2F116-IA359\%3Ade\&lang=de\&type=show_document $>$ accessed 24 September 2020.

101 'EIU Democracy Index 2019 - World Democracy Report' (2019)<http://www.eiu.com/topic/democracyindex $>$ accessed 24 September 2020.
} 
Perfecting them meant one thing: ensuring that the system of arbitrary segregation of the world's population is more engrained and ever unavoidable in its mission.

While sexism has somewhat waned away, structural racism, although officially proclaimed to have been dealt with - is with us until this day. After decolonization was accomplished following the second world war, the former colonial subjects are now confined to places around the world reserved uniquely for the losers of Ayelet Shachar's infamous 'birthright lottery'. ${ }^{102}$ Hence, the racist world has both changed and remained the same. It changed, because in the second half of the twentieth century, the western world has started to accept women's rights. Furthermore, racial and indigenous minorities within 'first world' states are also respected in many cases. It remained the same, since those who used to be confined to racialized secondclass statuses de facto or de jure in the former empires now inhabit sovereign decolonised states and are thus issued at times even worse statuses of attachment to authority in terms of rights and entitlements compared with their own colonial masters. The strict operation of identity management at the border crossing points and by airlines and ferry companies ensures that the former colonial subjects - now proclaimed free and equal - are kept at bay, finding the majority of the boundaries of the 'first world' legally impenetrable. At this point it seems unlikely that Blockchain would significantly change any of these established dynamics.

${ }^{102}$ Shachar (n 31). 